Article

\title{
Analytical Study of the Solidification of a Phase Change Material in an Annular Space
}

\author{
Zygmunt Lipnicki ${ }^{1, *}$ and Tomasz Małolepszy ${ }^{2}$ \\ 1 Institute of Environmental Engineering, University of Zielona Góra, 65-516 Zielona Góra, Poland \\ 2 Institute of Mathematics, University of Zielona Góra, 65-516 Zielona Góra, Poland; \\ t.malolepszy@im.uz.zgora.pl \\ * Correspondence: z.lipnicki@iis.uz.zgora.pl
}

Received: 25 September 2020; Accepted: 19 October 2020; Published: 23 October 2020

\begin{abstract}
In this study, the process of the solidification of a PCM (phase change material) liquid in an annular space was analytically investigated with the use of a simplified quasi-steady-state model. This model described the phase change phenomenon with the cylindrical solidification front and with the solidification liquid overheated above the solidification temperature. One of the important novelties of the applied model was the determination of the coefficient of the heat transfer between the liquid and the solidified layer on the solidification surface, which was calculated as a function of the location of the solidification front. A method for calculating the variable coefficient of heat transfer on the surface of the solidification front during the solidification process is presented. The contact layer between the cold wall and the solidified layer was incorporated into the model and played an important role. The theoretical analytical method describing the solidification process based on the quasi-steady model was used in the study. Moreover, the main problem considered in this work could be reduced to a conjugate system of differential equations, allowing it to be solved numerically. From this perspective, the influence of various dimensionless parameters on the solidification process could be clearly seen. The obtained numerical results are presented in graphical form. The results of the theoretical research were compared with the experimental research of one of the author's earlier works and they showed a significant agreement. Finally, the simple analytical approach presented in this work can be used for designing annular heat accumulators.
\end{abstract}

Keywords: phase change material (PCM); solidification in an annular space; heat transfer coefficient on solidification front; overheated liquid; heat accumulator

\section{Introduction}

Heat storage using phase change materials (PCMs) is very important in the energy sector. Due to the benefits of this method of heat storage, it is widely studied by many authors. Special benefits include the possibility of storing relatively large amounts of heat in a small volume of PCM material and a constant transition temperature. However, the disadvantage of PCM materials is their low thermal conductivity. This property extends the duration of the process. Therefore, it seems appropriate to search for the optimal shape of the outer material, i.e., increasing the outer surface. There is a need for additional testing of various geometric shapes of PCM materials due to storage and heat release conditions. This work focused on the study of PCM materials with an annular shape.

There have been a lot of studies in the scientific and professional literature on the subject of PCM solidification. One of the first papers investigating the solidification of liquids in cylindrical spaces is the work of Tao [1], who presented a numerical method for finding the generalized solutions to the moving interface problem of freezing a saturated liquid inside a cylindrical container with a constant heat transfer coefficient. The frozen solid phase had a constant heat capacity. 
A good overview of the existing literature in the field of PCM solidification is provided in [2-6]. In the aforementioned papers, the authors presented the following studies: Cheung and Epstein [2] investigated the solidification and the melting of flowing liquid in channels; the works of Viskanta [3,4] were dedicated to the solidification of metals and the solar heat storage, respectively; Weigand et al. [5] presented the solidification in forced convection flows inside ducts; Sinha and Gupta [6] studied solidification in an annulus. As can be seen from the presented papers, there are no works closely related to the subject of this paper.

The natural convection and solidification in a vertical annular enclosure were studied experimentally and theoretically in the work of Lipnicki et al. [7]. Here, the inner cylinder of the annular enclosure was cooled below the solidification temperature of the water, while the outer cylinder was kept at a constant temperature. Based on the above studies, in order to enhance the heat transfer performance of the latent heat storage, an active stirring heat transfer model was proposed and the effect of convection on the phase change heat transfer process was studied.

In the work of Gortych et al. [8], the solidification process of phase change materials in a horizontal annular enclosure was studied, both experimentally and theoretically. This work investigated the effect of free convection on the solidification process of a liquid in a horizontal annular channel, which was shown to be rather moderate. However, the theoretical model of solidification in the annular channel studied in this work assumed a constant temperature of the outer wall, which does not always correspond to real solidification conditions.

In the work of Pourakabar and Darzi [9], the enhancement of the phase change rate of a PCM was investigated numerically for a system of horizontal cylinders placed inside a circular and an elliptical shell with different arrangements.

The careful study of the problem of solidification in an annular enclosure should also take into account the thermal resistance of the contact layer between the cooled wall and the solidified layer. The analysis of the role of the contact layer in the solidification process was recently studied experimentally and theoretically by Loulou et al. [10-12], and theoretically by Weigand and Lipnicki et al. $[13,14]$. These works show that the influence of the contact layer between the cooled wall and the solidified layer on the solidification process is important.

One of the advantages of phase change heat storage is a high energy density. However, a lot of phase change materials have a low thermal conductivity; therefore, to improve the heat transfer, among other properties, an active stirring heat transfer model was proposed in the paper of Zhang et al. [15].

The literature review lacks studies presenting practical methods for designing heat accumulators that could be used in the energy sector. Therefore, one of the main aims of this study was to propose a simple and useful method for designing annular heat accumulators, with a particular emphasis on the heat transfer efficiency. A method of solving quasi-stationary heat conduction equations for overheated liquids, which are common in practice, was also proposed.

\section{Materials and Methods}

In order to solve the problem, we used a theoretical model involving an analytical method, which turned out to be a very effective and transparent method. In addition, the presented research method enables power engineers to design heat accumulators.

\subsection{Simple Analytical Model of the Solidification in an Annular Space}

The subject of this work was the solidification of a liquid placed in an annular space, as shown in Figure 1.

In this space, the solidification cylindrical front with radius $r$ moves from the cylindrical cooling surface with radius $R_{1}$ to the outer surface with radius $R_{2}$. The inner surface with radius $R_{1}$ is cooled by the flowing coolant in the annular space between radii $R_{0}$ and $R_{1}$. The heat stream of solidification $\dot{q}$ flows into the coolant. Additionally, $T_{C}$ here denotes the temperature of the liquid coolant, $T_{W}$ 
denotes the wall temperature, $\bar{T}$ denotes the temperature on the inner wall of the solidified layer, $T_{F^{-}}$ solidification temperature and finally, $T_{p}$ denotes the liquid temperature.

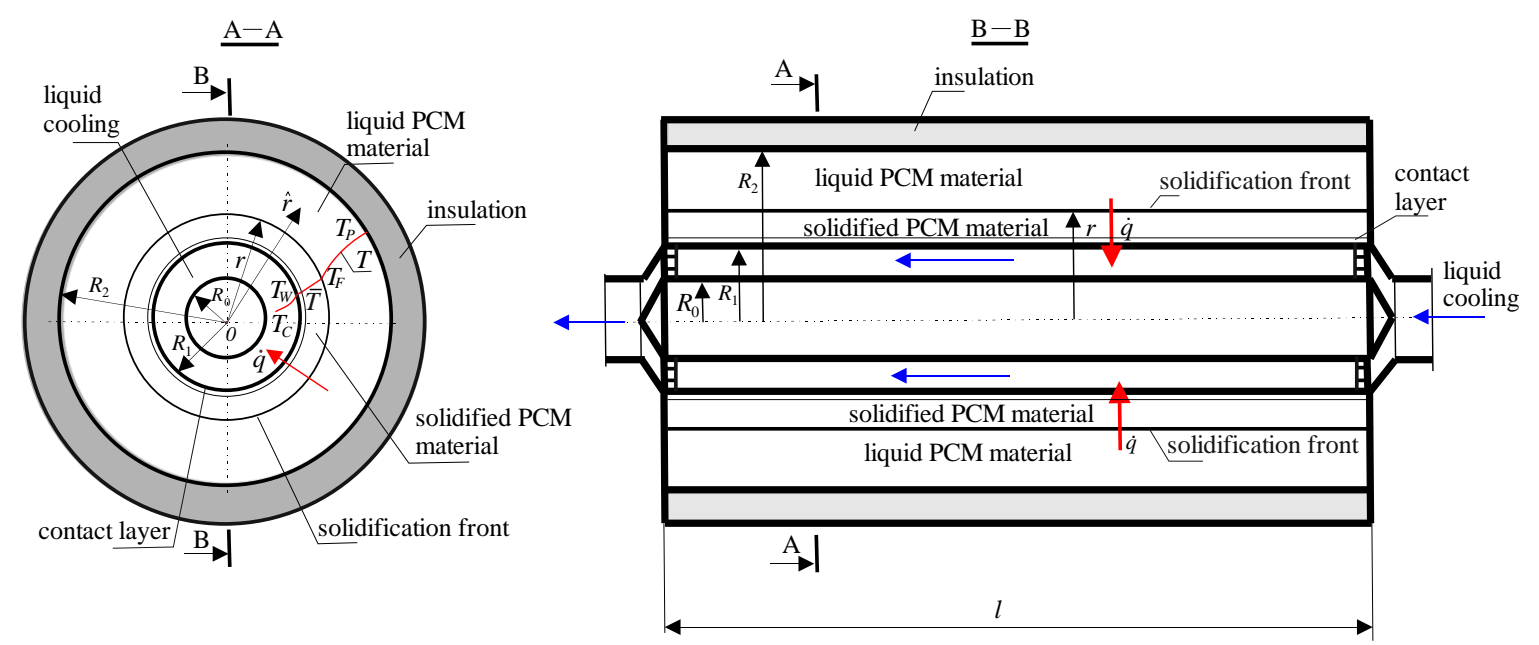

Figure 1. Solidification in an annular space. PCM: phase change material.

\subsection{Classical Stefan Problem and Quasi-Steady Solidification}

Generally, solidification processes are non-stationary and finding a solution to these problems usually reduces to solving non-stationary equations, namely, the Fourier heat equation in a solidified space and the Kirchhoff-Fourier energy conservation equation in a liquid-filled space. The two aforementioned spaces are separated by a moving solidification surface, also known as the solidification front. In the literature, such a problem is called a classical Stefan problem [16] and the boundary condition specified on the moving solidification front is called a Stefan condition ([17] is a comprehensive source on this subject). In most cases, the analytical solution to a Stefan moving boundary problem cannot be found; in such cases, numerical methods, as well as asymptotic or perturbation techniques, should be used. On the other hand, one of the methods for solving the solidification problem is to treat this phenomenon as a quasi-steady process. As the studies related to phase transitions show [18,19], solving the corresponding quasi-steady models is relatively easy and the received results are quite satisfactory when compared with exact solutions. For small values of the ratio of the heat capacity of the PCM material to the phase change heat of that material, which corresponds to allow Stefan number (i.e., Ste $\ll 1$ ), the use of quasi-steady models is justified and the accuracy of the obtained results is very high.

\subsection{Assumptions about a Stationary Liquid}

In general, the unevenly heated liquid in the field of Earth's gravity is subject to the phenomenon of free convection, which is described in the literature using the classical Boussinesq approximation [20].

In the theoretical model proposed in this study, the free convection of a liquid that has not yet been solidified is ignored. The heat flow in the fluid is assumed to be caused only by conduction. Such a simplification is justified by the assumption of a thin layer of solidifying liquid. The buoyancy movement of the liquid caused by the change in the density of the liquid due to the temperature change is inhibited by the surfaces of the external walls surrounding the liquid. Therefore, the phenomenon of free convection for thin liquid layers can be ignored in the theoretical considerations. Moreover, due to the interaction of the surfaces surrounding the liquid layer, the liquid can be treated as stationary, where such a model was adopted in this paper. 


\subsection{Mathematical Model Andits Analysis}

The temperature fields in both cases, i.e., in the liquid space $r(t)<\hat{r}<R_{2}$ and in the solidifiedlayer space $R_{1}<\hat{r}<r(t)$, where $\hat{r}$ denotes a radial coordinate, are described by the same quasi-stationary differential equation:

$$
\frac{d}{d \hat{r}}\left(\hat{r} \frac{d T}{d \hat{r}}\right)=0,
$$

Complete with the following boundary conditions:

- $\quad$ for the solidified layer space

$$
T=T_{F} \text { for } \hat{r}=r \text { and } T=\bar{T} \text { for } \hat{r}=R_{1},
$$

- $\quad$ for the liquid space

$$
T=T_{F} \text { for } \hat{r}=r .
$$

In addition, let:

$$
\bar{T}_{P}(t)=\frac{2 \int_{r}^{R_{2}} T(\hat{r}) \hat{r} d \hat{r}}{R_{2}^{2}-r^{2}},
$$

i.e., $\bar{T}_{P}(t)$ is the average temperature of the liquid in the space $r(t)<\hat{r}<R_{2}$.

Remark 1. Considering the implicit condition (4) instead of a typical boundary condition for $\hat{r}=R_{2}$ has the advantage that it allows for ensuring the existence of the solution of Equation (1). This is not always the case as, for instance, for overheated liquids $T>T_{F}$ in the area of a stationary liquid, the stationary solution of Equation (1) with a pair of classical boundary conditions: for $\hat{r}=r, T=T_{F}$, and $\hat{r}=R_{2}, \partial T / \partial \hat{r}=0$ simply does not exist.

The solutions of Equation (1) with conditions (2) and (3)-(4), respectively, give not only the temperature distribution in both spaces, i.e.:

$$
\begin{gathered}
T=T_{F}+\frac{T_{F}-\bar{T}}{\ln \frac{r}{R_{1}}} \ln \frac{\hat{r}}{r^{\prime}}, \ldots R_{1}<\hat{r}<r(t), \\
T=T_{F}+\frac{\bar{T}_{P}-T_{F}}{\frac{R_{2}^{2}}{R_{2}^{2}-r^{2}} \ln \frac{R_{2}}{r}-\frac{1}{2}} \ln \frac{\hat{r}}{r}, \ldots r(t)<\hat{r}<R_{2},
\end{gathered}
$$

but also the heat flux in the solidified layer space:

$$
\dot{q}=-\left.2 \pi k_{S} r \frac{\partial T}{\partial \hat{r}}\right|_{\hat{r}=r}=-2 \pi k_{S} \frac{T_{F}-\bar{T}}{\ln \frac{r}{R_{1}}},
$$

and the heat flux on the solidification front in the liquid space:

$$
\dot{q}=\left.2 \pi k_{L} r \frac{\partial T}{\partial \hat{r}}\right|_{\hat{r}=r}=2 \pi k_{L} \frac{\bar{T}_{P}-T_{F}}{\frac{R_{2}^{2}}{R_{2}^{2}-r^{2}} \ln \frac{R_{2}}{r}-\frac{1}{2}} .
$$

(for the full meaning of symbols used for the first time, please, check the Nomenclature table on page 10).

In addition, the heat flux absorbed from the liquid by the solidification front is equal to:

$$
\dot{q}=2 \pi r h(r)\left(\bar{T}_{P}-T_{F}\right) .
$$


Comparing heat fluxes (8) and (9), one can obtain the heat transfer coefficient $h(r)$ on a cylindrical surface with a radius $r$ on the liquid side, namely:

$$
h(r)=\frac{k_{L}}{r\left(\frac{R_{2}^{2}}{R_{2}^{2}-r^{2}} \ln \frac{R_{2}}{r}-\frac{1}{2}\right)} .
$$

The balance of the heat fluxes (see Figure 1), namely, the flux that is taken from the overheated PCM liquid and generated as a result of solidification of the PCM liquid, the flux conducted through the solidified layer, and finally, the flux conducted through the contact layer and taken over by the cooling liquid, give the following equalities $($ Ste $\ll 1)$ :

$$
\begin{gathered}
2 \pi r h(r)\left(\bar{T}_{p}-T_{F}\right)+2 \pi \rho_{S} L r \frac{d r}{d t}=-\left.2 \pi k_{S} r \frac{\partial T}{\partial \hat{r}}\right|_{\hat{r}=r}=2 \pi R_{1} h_{\mathrm{CON}}\left(\bar{T}-T_{W}\right)= \\
2 \pi R_{1} h_{C}\left(T_{W}-T_{C}\right)
\end{gathered}
$$

where such a simplified description of the solidification phenomenon is justified by its long duration.

Furthermore, the heat flux absorbed from the overheated liquid PCM is equal to the heat capacity change in the liquid annulus for the duration of the solidification phenomenon:

$$
2 \pi r h(r)\left(\bar{T}_{p}-T_{F}\right)=-\frac{d}{d t}\left[\pi\left(R_{2}^{2}-r^{2}\right) \rho_{L} c_{L}\left(\bar{T}_{P}-T_{F}\right)\right],
$$

where:

$$
\bar{T}_{P}(t)-T_{F}=\frac{2 \pi \int_{r}^{R_{2}}\left(T_{P}-T_{F}\right) \hat{r} d \hat{r}}{\pi\left(R_{2}^{2}-r^{2}\right)}
$$

is the average liquid overheating temperature.

The suitable transformation of Equation (11) leads to the following equation of heat flux balance:

$$
r h(r)\left(\bar{T}_{P}-T_{F}\right)+\rho_{S} L r \frac{d r}{d t}=k_{S} \frac{R_{1} h_{C O N} h_{C}}{h_{C O N} k_{S}+h_{C} k_{S}+h_{C} h_{C O N} R_{1} \ln \frac{r}{R^{1}}}\left(T_{F}-T_{C}\right) .
$$

A system of differential Equations (12)-(13) can now be converted to the dimensionless system:

$$
\begin{aligned}
\frac{\widetilde{k} B}{\left(\frac{1}{1-s^{2} \vec{r}^{2}} \ln \frac{1}{\tilde{s}}-\frac{1}{2}\right)} \bar{\theta}_{P}+\widetilde{r} \frac{d \vec{r}}{d \tau}=\frac{B i_{C} B i_{C O N}}{B i_{C}+B i_{C O N}+B i_{C} B i_{C O N} \ln \vec{r}} \\
\frac{2}{\left(\frac{1}{1-s^{2} \widetilde{r}^{2}} \ln \frac{1}{s \widetilde{r}}-\frac{1}{2}\right)} \bar{\theta}_{P}=-\frac{S t e}{s^{2} \widetilde{a}} \frac{d}{d \tau}\left[\left(1-s^{2} \widetilde{r}^{2}\right) \bar{\theta}_{P}\right],
\end{aligned}
$$

by introducing dimensionless quantities as follows: a radius $\widetilde{r}=r / R_{1}$; a time $\tau=$ FoSte; the average overheating temperature of the liquid $\bar{\theta}_{p}=\left(\bar{T}_{p}-T_{F}\right) /\left(T_{P 0}-T_{F}\right)$, where $T_{P 0}$ is the initial temperature of liquid PCM material; the ratio of cylinder radii $s=R_{1} / R_{2}$; the Fourier number Fo $=a_{S} t / R_{1}^{2}$; the Stefan number Ste $=c_{S}\left(T_{F}-T_{C}\right) / L$; the thermal diffusion coefficient of the solidified layer $a_{S}=k_{S} /\left(\rho_{S} c_{S}\right)$; the liquid thermal diffusion coefficient $a_{L}=k_{L} /\left(\rho_{L} c_{L}\right)$; the Biot number in the contact layer $B i_{\mathrm{CON}}=h_{\mathrm{CON}} R_{1} / k_{S}$; the Biot number on the surface of the inner cylinder $B i_{C}=h_{C} R_{1} / k_{s}$; the liquid overheating parameter $B=\left(T_{P 0}-T_{F}\right) /\left(T_{F}-T_{C}\right)$; the ratio of liquid and solid heat diffusion coefficients $\widetilde{a}=a_{L} / a_{S}$; the ratio of liquid and solid heat conduction coefficients $\widetilde{k}=k_{L} / k_{S}$.

Unknown functions $\widetilde{r}(\tau)$ and $\bar{\theta}_{P}(\tau)$ in the system (14)-(15) also fulfill the initial conditions:

$$
\widetilde{r}=1, \bar{\theta}_{P}=1 \text { for } \tau=0,
$$

where they can be found numerically. 
A similar analysis is done in the case of an unheated liquid $(B=0)$, which results in only one differential equation:

$$
\widetilde{r} \frac{d r}{d \tau}=\frac{B i_{C} B i_{C O N}}{B i_{C}+B i_{C O N}+B i_{C} B i_{C O N} \ln \vec{r}}
$$

which, together with the initial condition:

$$
\widetilde{r}=1 \text { for } \tau=0
$$

allows for determining the solidification time $\tau$ in terms of $\widetilde{r}$ :

$$
\tau=\left(\frac{1}{2} \frac{B i_{C}+B i_{C O N}}{B i_{C} B i_{C O N}}-\frac{1}{4}\right)\left(\vec{r}^{2}-1\right)+\frac{1}{2} \vec{r}^{2} \ln \tilde{r},
$$

and as a consequence, the total solidification time $\tau_{t}$, i.e., time for which $\widetilde{r}\left(\tau_{t}\right)=1 / s$ :

$$
\tau_{t}=\left(\frac{1}{2} \frac{B i_{C}+B i_{C O N}}{B i_{C} B i_{C O N}}-\frac{1}{4}\right) \frac{1-s^{2}}{s^{2}}-\frac{\ln s}{2 s^{2}} .
$$

Because

$$
\frac{d \tau_{t}}{d s}=\left(\ln s-\frac{B i_{C}+B i_{C O N}}{B i_{C} B i_{C O N}}\right) \frac{1}{s^{3}},
$$

it is easy to notice that for arbitrary $B i_{C}, B i_{C O N}>0$ the total solidification time, as a function of parameter $s$, will always be decreasing, provided that $0<s<1$.

\subsection{Computing the Heat Transfer Coefficient $h_{C}$}

Equation (10) allows for computing the heat transfer coefficient $h$ on a cylindrical surface. On the other hand, another important parameter related to the heat transfer, namely, the heat transfer coefficient $h_{C}$ inside the cooled cylinder (which is very useful in finding the Biot number $B i_{C}$ on the surface of the inner cylinder), can be calculated according to [21,22] with the help of the average Nusselt number $N u_{C}$ in the annular channel inside the cooled annular cylinder. One can compute this Nusselt number according to the following formula [23]:

$$
\frac{N u_{C}}{N u_{z, \infty}}=1+C^{\prime} G z,
$$

where the Nusselt number $N u_{z, \infty}[21,22]$ is the value for a fully developed flow in the annular channel, $\mathrm{G} z$ is the Graetz number, and $C^{\prime}$ is a constant, with the last two defined respectively by:

$$
G z=\frac{\dot{m} c_{C}}{k_{C} l} \text { and } C^{\prime}=0.00745 \frac{\beta}{1+\beta} .
$$

In Equation (21), $\dot{m}$ is the mass flow rate of the cooling liquid, $c_{C}$ is the specific heat capacity of the cooling liquid, $k_{C}$ is the thermal conductivity of the cooling liquid, $l$ is the annular channel length, and the parameter $\beta$ is equal to the ratio of the external $R_{1}$ to the internal radius $R_{0}$ of the annular cooling channel. These thermodynamic parameters for the cooling liquid can be found, for instance, in $[23,24]$. Finally, the heat transfer coefficient at the inner surface $h_{C}$ of the cold cylinder is equal to:

$$
h_{C}=\frac{N u_{C} k_{C}}{D_{h}}
$$

where $D_{h}=2\left(R_{1}-R_{0}\right)$ is the hydraulic diameter of the annular channel. 


\section{Results and Discussion}

\subsection{Heat Transfer Coefficient}

The dependence of the heat transfer coefficient in the dimensionless form on the position of the solidification front is shown in Figure 2. As this figure suggests, the heat transfer coefficient at the end of the solidification process became larger and larger (in fact it tended to infinity). However, because the overheating temperature decreased to zero, the product of these two quantities (see Equation (11)) was finite and physically justified. For the unheated liquid, this problem did not occur.

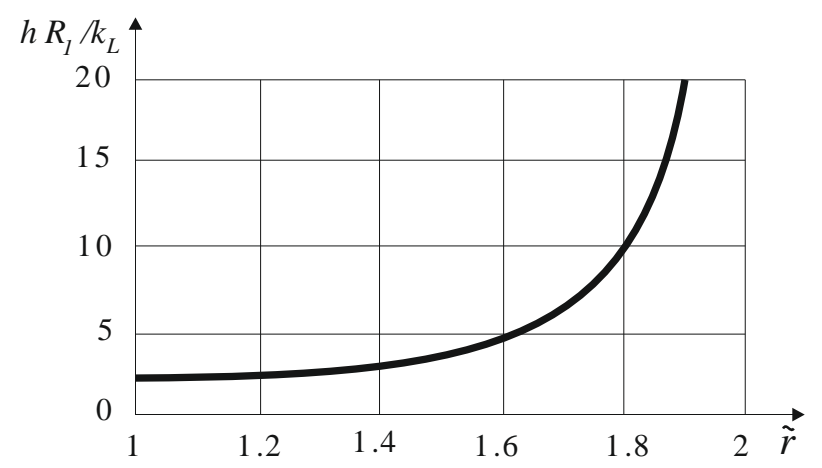

Figure 2. The dependence of the heat transfer coefficient on the position of the solidification front.

\subsection{Solidification of the Unheated vs. Heated Liquid}

The dependence of the position of the solidification front and the solidification rate on time in the case of an unheated liquid is presented in Figure 3.

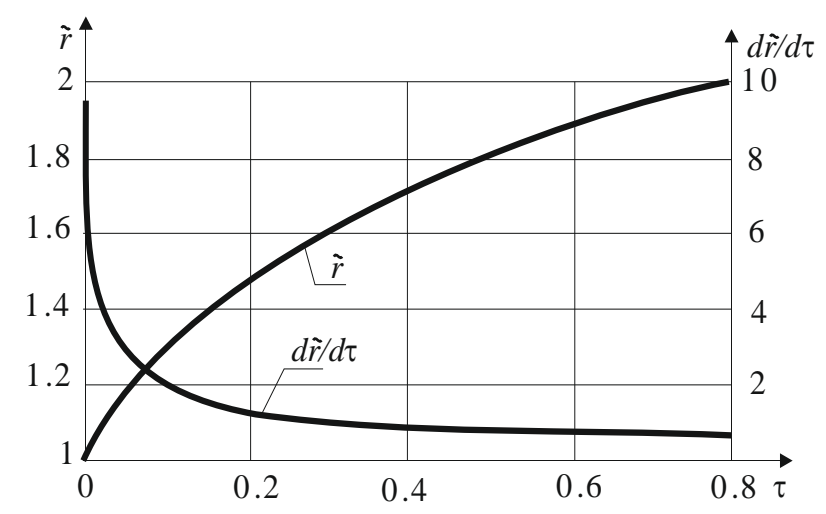

Figure 3. The dependence on the position of the solidification front and the solidification rate on time in an annular space for an unheated liquid $\left(s=0.5, B=0, B i_{C O N}=10, B i_{C}=177\right)$.

In Figure 4, on the other hand, the dependence of the position of the solidification front and the velocity of the solidification on time is shown, as well as the dependence of the average temperature and the position of the solidification front on time for a heated liquid.

The presented figures indicate that as the degree of overheating increased, the solidification time increased and the solidification velocity decreased. 


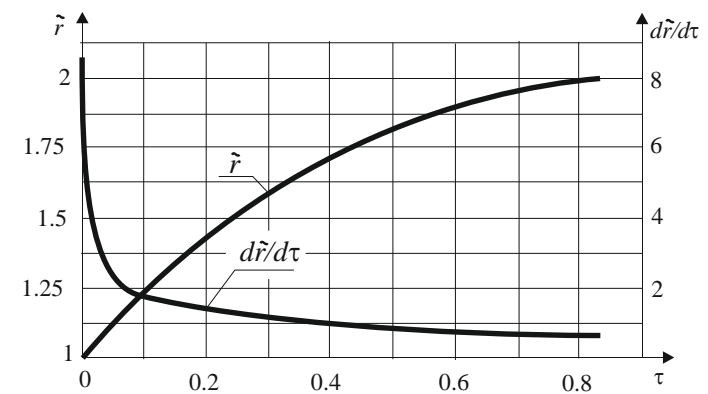

(a)

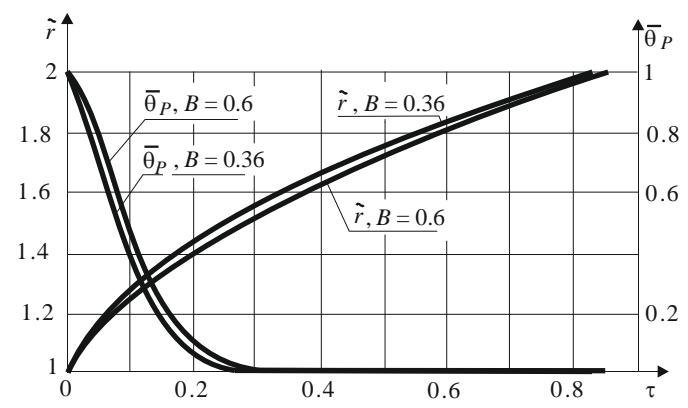

(b)

Figure 4. Numerical results for system (14)-(15) with parameters (Ste $=0.112, s=0.5, B i_{C O N}=$ $10, B i_{C}=177, \widetilde{k}=1, \widetilde{a}=0.886$ ) for a heated liquid: (a) the dependence of the position of the solidification front and the velocity of the solidification on time $(B=0.36)$ and $(\mathbf{b})$ the dependence of the average temperature and the position of the solidification front on time $(B=0.36$ and $B=0.6)$.

\subsection{Solidification Time}

The next figure, Figure 5, illustrates how the total solidification time depended on parameter s. In the case of an unheated liquid, one can use the analytical Equation (19) to graphically present such a dependence. It follows that with the increase of the parameter $s$ (in other words, with the decrease in the thickness of the solidifying layer), the solidification time decreased. Of course, this was consistent with the earlier observation regarding the negative sign of $d \tau_{t} / d s$ that was made at the end of Section 2.4.

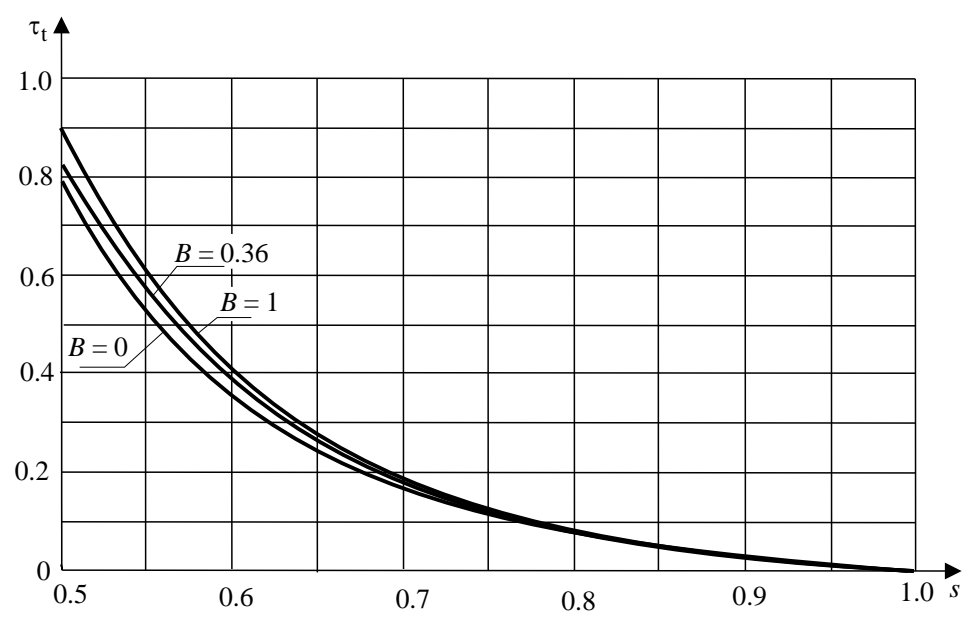

Figure 5. The dependence of the total solidification time on the parameter $s$ for various values of $B$ $\left(B i_{C O N}=10, B i_{C}=177\right.$; in the case of $B>0$, Ste $\left.=0.112, \widetilde{a}=0.886, \widetilde{k}=1\right)$.

Although for overheated liquids $(B>0)$, no analog of Equation (19) exists, numerical computations based on system (14)-(15) led to a conclusion where the dependence curves had similar shapes in this case. Moreover, Figure 5 confirms the simple and natural observation: for a fixed parameter $s$, the more the liquid is overheated, the longer it will take to solidify.

\subsection{CaseStudy for a Specific PCM (RT64HC) and Configuration}

The results in Table 1, which were computed both numerically and analytically for the heat accumulator with the following dimensions: $\beta=1.33, R_{0}=0.06 \mathrm{~m}, R_{1}=0.08 \mathrm{~m}, R_{2}=0.16 \mathrm{~m}$, and $l=1 \mathrm{~m}$ (see Figure 1), show that the solidification times for one of the commercial PCM materials, namely, RT64HC [25], were relatively large, which can be reduced by using very thin annular segments of PCM materials in heat accumulator design solutions. 
Table 1. The values of the main parameters for RT64HC.

\begin{tabular}{cccccccccccc}
\hline No & Coolant & $T_{C}(\mathbf{K})$ & $\dot{m} \mathbf{( k g / s )}$ & $G z$ & $N u_{C}$ & $S t e$ & $B$ & $B i_{C}$ & $B i_{C O N}$ & $\dot{Q}_{0}(\mathbf{W})$ & $t_{t}(\mathbf{h})$ \\
\hline 1 & Water & 323 & 0.1 & 749 & 31.5 & 0.112 & 0 & 177 & 10 & 166.4 & 110.7 \\
\hline 2 & Water & 323 & 0.1 & 749 & 31.5 & 0.112 & 0.36 & 177 & 10 & 152.1 & 114.1 \\
\hline 3 & Water & 323 & 0.1 & 749 & 31.5 & 0.112 & 0.60 & 177 & 10 & 142.8 & 117.0 \\
\hline 4 & Water & 283 & 0.1 & 749 & 31.5 & 0.432 & 0 & 177 & 10 & 642.0 & 28.7 \\
\hline 5 & Ethylene glycol & 273 & 0.1 & 780 & 32.5 & 0.512 & 0 & 133 & 10 & 747.1 & 24.3 \\
\hline 6 & Ethylene glycol & 263 & 0.1 & 780 & 32.5 & 0.592 & 0 & 133 & 10 & 863.9 & 21.0 \\
\hline
\end{tabular}

Figure 6 shows the temperature distribution in the solidified layer for RT64HC for the different freezing steps. Temperature distributions at steady times are described by logarithmic functions (5); however, graphically, the presented shapes are similar to linear functions, where the slopes of which decreased with increasing time.

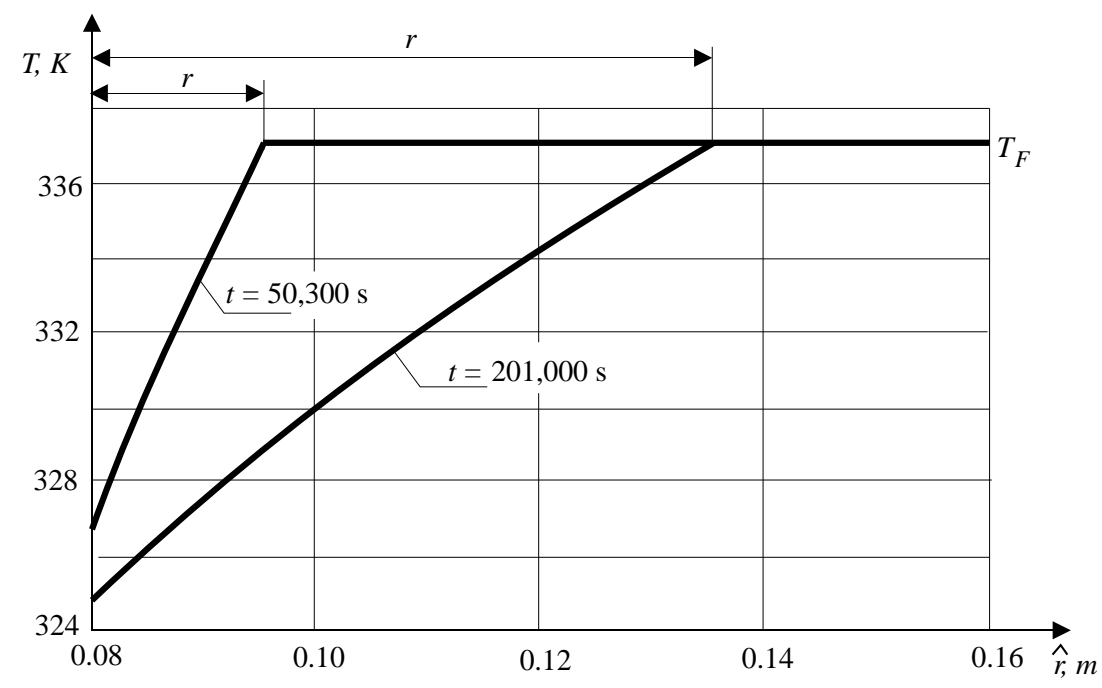

Figure 6. Temperature distribution in the solidified layer for $\operatorname{RT} 64 \mathrm{HC}\left(B=0, B i_{C O N}=10\right.$, $\left.B i_{C}=177, s=0.5\right)$.

\subsection{Analysis of the Layer Thickness of the Solidifying PCM Material}

The influence of the thickness of the PCM material layer on the discharge time of the heat accumulator (in other words, on the solidification process) was very significant. As mentioned earlier, PCM materials are mostly bad heat conductors. The thermal conductivity parameter of a PCM affects the solidification rate of the liquid, and hence the discharge time of the heat accumulator. In order to solve this problem, it is worth analyzing the influence of the thickness of the annular layer on the solidification process from a thermodynamic perspective, in particular, on the solidification time. Such an analysis ultimately leads to a defragmentation of the volume of the PCM material. Unfortunately, this operation could lead to reducing the total mass of the material and, as a consequence, to decreasing the amount of stored heat. In an attempt to prevent this undesirable effect, the number of annular layers should be increased, which translates not only to an increase in the outer surface of the PCM material but also, indirectly, to an increase in the heat flux transferred to the outside. This also suggests that a ratio of the volume to area, which is used in metal casting and is called the reduced solidification layer thickness, would be a very useful parameter to also consider when designing heat accumulators based on PCM materials. 


\subsection{Comparison of the Theoretical Model with Experimental Data}

Figure 7 shows a comparison of the experimental research [8] with the theoretical model studied in this work for similar external conditions. Theoretical calculations were made for water, which played the role of the PCM material in the aforementioned experiment, with the following parameters being used: Ste $=0.04, B i_{C}=13, B i_{C O N}=10, B=1.5, s=0.5, \widetilde{a}=8.2$, and $\widetilde{k}=0.26$. As one can see, both sets of data showed significant agreement, which indicates the correctness of the theoretical model.

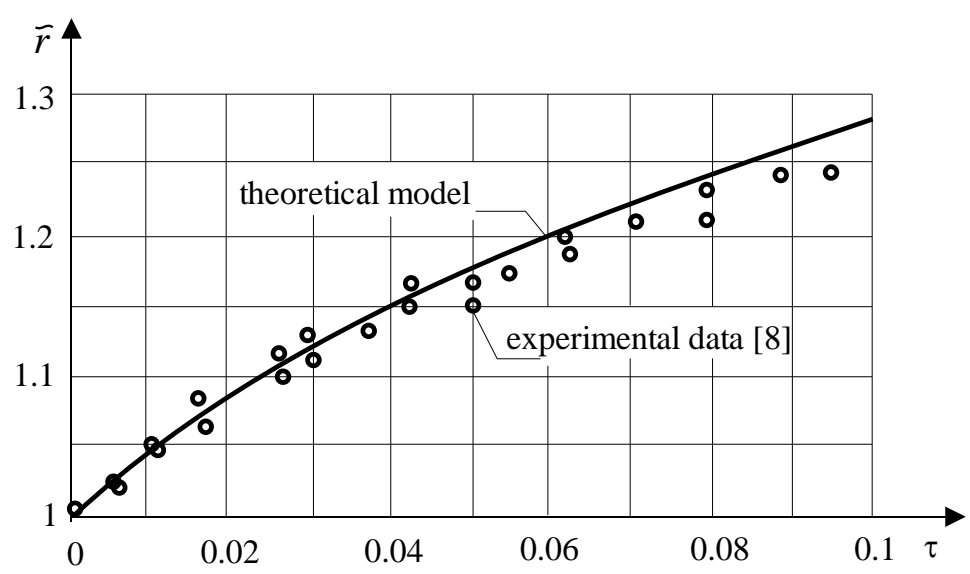

Figure 7. Comparison of the theoretical model with the data from the experiment.

\section{Conclusions}

A full analytical solution to the problem of the solidification and the heat transfer in a liquid and a solidified layer using the quasi-stationary Fourier equation in an annular space requires a suitable setting of boundary conditions in order not to trivialize the solutions. This paper presents a simple way of calculating the heat transfer coefficient $h(r)$ of the solidification surface (see Equation (10)), which is of great importance and plays a great role in solving the solidification problem.

Because PCM materials are generally poor conductors, the total solidification times of a PCM liquid in an annular heat accumulator for the determined mass were quite long, as can be seen from Table 1 . The solidification time depended on the value of the overheating parameter $B$, the temperature of the cooling liquid $T_{C}$, the heat transfer coefficient $h_{C}$ to the coolant, and the Stefan number Ste, among other variables. From the analysis of Equations (14) and (15), it followed that the solidification time also depended heavily on the thickness of the annular cylindrical layer of the PCM material (i.e., parameter $s$ ). Therefore, we suggest building heat accumulators that consist of a large number of thin annular layers. While maintaining an appropriate total mass of PCM material is necessary in order to store a sufficient amount of heat, the number of annular segments should be increased, leading to an increase in the outer surface of the total PCM material, which in turn causes an increase in the thermal power of the heat accumulator.

Author Contributions: Conceptualization, Z.L.; methodology, Z.L. and T.M.; software T.M.; validation, Z.L. and T.M.; formal analysis, Z.L. and T.M.; writing-original draft preparation, Z.L. and T.M.; writing-review and editing, Z.L. and T.M.; visualization, Z.L. and T.M.; supervision, Z.L. All authors have read and agreed to the published version of the manuscript.

Funding: This research received no external funding.

Conflicts of Interest: The authors declare no conflict of interest. 


\section{Nomenclature}

$a_{S} \quad$ thermal diffusivity of the solidified layer, $\mathrm{m}^{2} / \mathrm{s}$

$a_{L} \quad$ thermal diffusivity of the liquid, $\mathrm{m}^{2} / \mathrm{s}$

$c_{S} \quad$ specific heat of the solidified layer, $\mathrm{J} /(\mathrm{kgK})$

$c_{L} \quad$ specific heat of the liquid, $\mathrm{J} /(\mathrm{kgK})$

$c_{C} \quad$ specific heat of the cooling liquid, $\mathrm{J} /(\mathrm{kgK})$

$h$ heat transfer coefficient at the solidification front, $\mathrm{W} /\left(\mathrm{m}^{2} \mathrm{~K}\right)$

$h_{C} \quad$ heat transfer coefficient at the inner cylinder, $\mathrm{W} /\left(\mathrm{m}^{2} \mathrm{~K}\right)$

$h_{\mathrm{CON}} \quad$ heat transfer coefficient in the contact layer, $\mathrm{W} /\left(\mathrm{m}^{2} \mathrm{~K}\right)$

$k_{L} \quad$ heat conductivity of the liquid, $\mathrm{W} /(\mathrm{mK})$

$k_{S} \quad$ heat conductivity of the solidified layer, $\mathrm{W} /(\mathrm{mK})$

$k_{\mathrm{C}} \quad$ heat conductivity of the cooling liquid, $\mathrm{W} /(\mathrm{mK})$

$l \quad$ length of the channel, $\mathrm{m}$

$L \quad$ latent heat of the liquid, $\mathrm{J} / \mathrm{kg}$

$\dot{q} \quad$ heat flux, $\mathrm{W} / \mathrm{m}$

$\dot{Q}_{0} \quad$ initial heat flux, $\mathrm{W}$

$\hat{r} \quad$ radial coordinate, $\mathrm{m}$

$r \quad$ radius of the solidification front, $\mathrm{m}$

$R_{0} \quad$ radius of the cylinder inside the accumulator, $\mathrm{m}$

$R_{1} \quad$ radius of the inner cylinder, $\mathrm{m}$

$R_{2} \quad$ radius of the outer cylinder, $\mathrm{m}$

$D_{h} \quad$ hydraulic diameter of the annular channel, $=2\left(R_{1}-R_{0}\right), \mathrm{m}$

$t$ time, $\mathrm{s}$ or $\mathrm{h}$

$t_{t} \quad$ total solidification time, $\mathrm{h}$

$T \quad$ temperature, $\mathrm{K}$

$T_{W} \quad$ wall temperature of the inner cylinder, $\mathrm{K}$

$T_{F} \quad$ solidification temperature, $\mathrm{K}$

$T_{P} \quad$ liquid temperature, $\mathrm{K}$

$\bar{T}_{P} \quad$ average liquid temperature, $\mathrm{K}$

$T_{P 0} \quad$ initial liquid temperature, $\mathrm{K}$

$T_{C} \quad$ temperature of the liquid coolant, $\mathrm{K}$

$\bar{T} \quad$ temperature of the inner wall of the solidified layer, $\mathrm{K}$

Dimensionless numbers

$\widetilde{a} \quad$ ratio of thermal diffusivities, $=a_{L} / a_{S}$

$\widetilde{r} \quad$ dimensionless radius, $=r / R_{1}$

$\mathrm{s} \quad$ ratio of the cylinder radii, $=R_{1} / R_{2}$

$\tilde{k} \quad$ ratio of the heat conductivities, $=k_{L} / k_{S}$

$\tau \quad$ dimensionless time, $=$ SteFo

$\tau_{t} \quad$ dimensionless total solidification time, $=$ SteFo

$\bar{\theta}_{P} \quad$ average dimensionless temperature of the liquid, $=\left(\bar{T}_{P}-T_{F}\right) /\left(T_{P 0}-T_{F}\right)$

$B \quad$ overheating parameter, $=\left(T_{P 0}-T_{F}\right) /\left(T_{F}-T_{C}\right)$

$B i_{C O N} \quad$ Biot number of the contact layer, $=h_{C O N} R_{1} / k_{S}$

$B i_{C} \quad$ Biot number on the surface of the inner cylinder, $=h_{C} R_{1} / k_{s}$

$\mathrm{Gz} \quad$ Graetz number, $=\dot{m_{c}} \mathrm{C} /\left(k_{\mathrm{C}} l\right)$

$N u_{C} \quad$ Nusselt number on the surface of the inner annular cylinder, $=h_{C} D_{h} / k_{C}$

Fo $\quad$ Fourier number, $=a_{S} t / R_{1}^{2}$

Ste Stefan number, $=c_{S}\left(T_{F}-T_{C}\right) / L$

Other Greek letters

$\beta \quad$ ratio of the cylinder radii, $=R_{1} / R_{0}$

$\rho_{L} \quad$ liquid density, $\mathrm{kg} / \mathrm{m}^{3}$

$\rho_{S} \quad$ density of the solidified layer, $\mathrm{kg} / \mathrm{m}^{3}$ 


\section{References}

1. Tao, L.C. Generalized numerical solutions of freezing a saturated liquid in cylinders and spheres. AIChE J. 1967, 13, 165-169. [CrossRef]

2. Cheung, F.B.; Epstein, M. Solidification and melting in fluid flow. In Advances in Transport Processes; Mujumdar, A.S., Mashelkar, R.A., Eds.; Wiley: New York, NY, USA, 1984; Volume III, pp. 35-117.

3. Viskanta, R. Heat Transfer During Melting and Solidification of Metals. J. Heat Transf. 1988, 110, 1205-1219. [CrossRef]

4. Viskanta, R. Phase-Change Heat Transfer in Solar Heat Storage. In Latent Heat Transfer; Lane, G.A., Ed.; CRS Press: Palm Beach, FL, USA, 1983; pp. 153-221.

5. Weigand, B.; Braun, J.; Neumann, S.O.; Rinck, K.J. Freezing in forced convection flows inside ducts: A review. Heat Mass Transf. 1997, 32, 341-351. [CrossRef]

6. Sinha, T.; Gupta, J. Solidification in an annulus. Int. J. Heat Mass Transf. 1982, 25, 1771-1773. [CrossRef]

7. Lipnicki, Z.; Weigand, B. An experimental and theoretical study of solidification in a free-convection flow inside a vertical annular enclosure. Int. J. Heat Mass Transf. 2012, 55, 655-664. [CrossRef]

8. Gortych, M.; Lipnicki, Z.; Weigand, B. An experimental and theoretical study of the solidification process of phase change materials in a horizontal annular enclosure. Appl. Therm. Eng. 2019, 161, 114-140. [CrossRef]

9. Pourakabar, A.; Darzi, A.A.R. Enhancement of phase change rate of PCM in cylindrical thermal energy storage. Appl. Therm. Eng. 2019, 150, 132-142. [CrossRef]

10. Loulou, T.; Artyukhin, E.; Bardon, J.P. Solidification of Molten Tin Drop on a Nickel Substrate. In Proceedings of the International Heat Transfer Conference 10, Brighton, UK, 14-18 August 1994; pp. 73-78.

11. Loulou, T.; Artyukhin, E.A.; Bardon, J.P. Estimation of thermal contact resistance during the first stages of metal solidification process: I-Experiment principle and modelisation. Int. J. Heat Mass Transf. 1999, 42, 2119-2127. [CrossRef]

12. Loulou, T.; Artyukhin, E.A.; Bardon, J.P. Estimation of thermal contact resistance during the first stages of metal solidification process: II-Experiment setup and results. Int. J. Heat Mass Transf. 1999, 42, $2129-2142$. [CrossRef]

13. Lipnicki, Z.; Weigand, B. Influence of the thermal boundary layer on the contact layer between a liquid and a cold plate in a solidification process. Heat Mass Transf. 2011, 47, 1629-1635. [CrossRef]

14. Weigand, B.; Lipnicki, Z. Development of the contact layer and its role in the phase change process. Int. J. Heat Mass Transf. 2016, 93, 1082-1088. [CrossRef]

15. Zhang, Y.; Liu, S.; Yang, L.; Yang, X.; Shen, Y.; Han, X. Experimental Study on the Strengthen Heat Transfer Performance of PCM by Active Stirring. Energies 2020, 13, 2238. [CrossRef]

16. Stefan, J. ÜbereinigeProbleme der Theorie der Wärmeleitung, Sitzungsber. Wien. Akad. Math. Naturw. 1889, 98, 473-484.

17. Gupta, S.C. The Classical Stefan Problem: Basic Concepts, Modelling and Analysis with Quasi-Analytical Solutions and Methods, 2nd ed.; Elsevier Science: Amsterdam, The Netherlands, 2017.

18. Plank, R. Über die Gefrierzeit von Eis und wasserhaltigenLebensmitteln, Z. ges. Kälteindustrie 1932, 39, 56-58.

19. Talar, J.; Duda, P. Rozwiazywanie Prostych i Odwrotnych Zagadnień Przewodzenia Ciepła; WNT: Warsaw, Poland, 2003.

20. Boussinesq, J. Théorieanalytique de la Chaleur: Mise Enharmonie Avec la Thermodynamique et Avec la Théoriemécanique de la Lumière; Gauthier-Villars: Paris, France, 1903; Volume 2.

21. Kays, W.M.; Whitelaw, J.H. Convective Heat and Mass Transfer. J. Appl. Mech. 1967, 34, 254. [CrossRef]

22. Madejski, J. Teoria Wymiany Ciepła; Wydawnictwo Uczelniane Politechniki Szczecińskiej: Szczecin, Poland, 1998.

23. Thermophysical Properties of Brines Models. Available online: http://www.mrc-eng.com/Downloads/Brine $\%$ 20Properties.pdf (accessed on 16 October 2020).

24. Kretzschmar, H.J.; Kraft, I. Kleine Formel Sammlung Technische Thermodynamik, 1st ed.; Carl Hanser Verlag: Munich, Germany, 2007. 
25. R T64HC—Data Sheet. Available online: https://www.rubitherm.eu/media/products/datasheets/Techdata_ -RT64HC_EN_06082018.PDF (accessed on 16 October 2020).

Publisher's Note: MDPI stays neutral with regard to jurisdictional claims in published maps and institutional affiliations.

(C) 2020 by the authors. Licensee MDPI, Basel, Switzerland. This article is an open access article distributed under the terms and conditions of the Creative Commons Attribution (CC BY) license (http://creativecommons.org/licenses/by/4.0/). 